\title{
EPR SPECTRA OF V(IV) COMPLEXES AND THE STRUCTURE OF OIL PORPHYRINS
}

\author{
L. G. Gilinskaya
}

UDC 537.635:538.113:548.737:552.578.3

For natural bitumoids, the effects of the structure of vanadyl-porphyrin complexes on the EPR spectra were investigated. The ambiguity of the hyperfine structure (its presence or absence) corresponding to four nitrogen atoms in the spectra of oil vanadyl porphyrins correlates with the changes in the second coordination sphere of the nearest environment of the metal ion, namely, in methine bridges.

Keywords: structure of porphyrins, vanadyl ion complexes, EPR spectra, natural bitumoid fractions.

\section{INTRODUCTION}

The natural organic matter $(\mathrm{OM})$ of the sedimentary rocks, both concentrated (oil) and scattered (bitumoid), is a complex compound where hydrocarbons are dominant (80-87\% carbon and 11-14\% hydrogen) and heteroatoms are present in minor amounts (HAs, \%: 0.01-5 sulfur, 0.04-6 nitrogen, and 0.2-3 oxygen). Other elements, including metals, amount to less than $1 \%$. These include most elements from the periodic table ( 60), called microelements by V. I. Vernadskii, namely, $\mathrm{V}, \mathrm{Ni}, \mathrm{Fe}, \mathrm{Co}, \mathrm{Cr}, \mathrm{Zn}, \mathrm{As}$, etc. whose content in the organic substance is small $\left(10^{-1}-10^{-7} \%\right)$. Along with the major elements of OM, microelements are constantly the objects of active research dictated by the geological, geochemical, industrial (raw materials), technological, and environmental challenges [1,2].

Vanadium is most widespread among the "biogenic" elements of oil; this is one of the three elements $(\mathrm{V}, \mathrm{Ni}, \mathrm{Fe})$ whose amount is relatively larger than the amounts of other elements $\left(10^{-1} \mathrm{~V}, \mathrm{Ni} ; 10^{-2} \mathrm{Fe}\right)$. Vanadium and nickel are closely related to the organic matter from which oil originated; their concentrations were found to depend on the type, age, and composition of the organic substance and are changed by secondary oil formation processes such as catagenesis, biodegradation, and migration [3]. Thus, vanadium and nickel are important genetic labels for solving geological and genetic problems in oil geology.

In 1934, A. Treibs [4] assumed that vanadium entered into oils in the form of porphyrin complexes. After the discovery of the EPR method (1944), it was firmly established that vanadium was present in oil in the form of $\mathrm{V}^{4+}$, which formed the vanadyl complex with oxygen $\left(\mathrm{V}^{4+}+\mathrm{O}^{2+} \rightarrow \mathrm{VO}^{2+}, 3 d^{1}, S=1 / 2\right)$ and entered into porphyrins [5]. Vanadyl porphyrins are still the only metal-containing components of oils that were structurally identified.

The typical EPR spectrum of vanadyl porphyrin complexes in solutions is isotropic and consists of eight hyperfine lines of ${ }^{51} \mathrm{~V}(J=7 / 2)$. In frozen solutions $(77 \mathrm{~K})$ and solid components of oils (asphaltenes, resins), the spectrum has an axial symmetry and consists of 16 lines with a hyperfine structure (hfs). Many publications gave the spectrum of $\mathrm{VO}^{2+}$ and its parameters and showed that the latter were almost constant for oils and their fractions with very different hydrocarbon groups and physicochemical features; the differences did not exceed the absolute errors of measurement [6-11].

Institute of Geology and Mineralogy, Siberian Division, Russian Academy of Sciences, Novosibirsk; lgilinskaya@igm.nsc.ru. Translated from Zhurnal Strukturnoi Khimii, Vol. 49, No. 2, pp. 259-268, March-April, 2008. Original article submitted June 19, 2007. 
In addition to vanadyl, oil contains free organic radicals (FRs); in the EPR spectrum, they are represented by a single isotropic line $(S=1 / 2)$ with an unresolved fine structure, arising from the interaction of the odd electron with the surrounding protons. The $g$ factor of the organic radical of the organic radical is mostly close to $g_{\mathrm{e}}=2.0023$, and the line width changes in the range of $\Delta H=0.4-0.7 \mathrm{mT}$ for samples with different compositions. The integrated intensity of absorption (concentration), $N_{x}(\mathrm{spin} / \mathrm{g})$, is another variable parameter of FRs.

According to modern concepts, the paramagnetism of the FR is determined by the electron localized on the broken bond in the side chains of the condensed rings of the aromatic structures [11]. Bond cleavage in aromatic structures may be represented as the result of thermal splitting of the carbon-hydrogen bond in the course of the formation of carbon rings. Elimination of the side groups from the ring gives rise to new $\mathrm{C}-\mathrm{C}$ bonds, which favors growth of the ring system. The reasons for the elimination of the side groups are the following processes: dehydroxylation (elimination of $\mathrm{OH}$ groups), demethylation (elimination of methyl groups, cleavage of the aliphatic chains due to the thermal vibrations of the carbon-hydrogen bonds, etc.

The EPR data are used in analysis of oils and oil products to determine the concentrations of vanadyl porphyrins and organic radicals that correlate with the formation conditions, paleoenvironmental records, and superimposed transformations. However, analysis of the EPR spectra of vanadyl porphyrins still encounters unresolved problems and controversies, while it would be interesting to find solution from the viewpoints of radiochemistry and coordination chemistry, which would expand the use of the data in oil geology. 1) It has not yet been stated specifically which types of porphyrin structures (homologs) form bonds with vanadium in natural masses. This knowledge is important because each oil-bearing region has a certain metalloporphyrin characteristic. 2) Vanadyl porphyrins are characterized by ambiguity of the superhyperfine splitting of the EPR lines of vanadyl from four nitrogen atoms, which could be expected from its structural position in porphyrins. In natural samples (asphaltenes), this was not observed, as shown by numerous studies [6,9, 10, 12, 13]. Only due to special enrichment of natural asphaltenes with synthetic porphyrins, the characteristic pattern of line splitting from the nitrogen atoms in the spectrum of vanadyl was recorded, and the $a_{\mathrm{N}}$ parameter was determined [14]. Moreover, superhyperfine structure (shfi) was not always observed for model porphyrins [5, 15]. The aim of this study is to solve problems that appeared in analysis of natural objects.

As shown by investigations, not only oils and bitumoids themselves, but also their heterocyclic components such as asphaltenes, asphaltogenic acids, and resins (benzene, benzene-alcohol) are carriers of genetic information, due to which they were used for oil survey, extraction, and processing and also in theoretical studies [16-19]. Current procedures allow one to isolate these components as polycrystalline solids; investigation of their EPR spectra precludes the dependence of the line width and shape on the sample viscosity, which makes it possible to observe the more informative anisotropic spectra at room temperature and thus to obtain more reliable results, especially when evaluating the concentration of the paramagnetic centers.

This work reports on the results of our investigation of the indicator peculiarities of the vanadium EPR spectra in four solid fractions of scattered organic matter (bitumoids) from the petroleogenetic rocks of West and East Siberia, isolated by the known procedures [20-22] at the Organic Geochemistry Laboratory of the Institute of Oil and Gas Geology, Siberian Division, Russian Academy of Sciences and subjected to EPR analysis at the Institute of Geology and Mineralogy, Siberian Division, Russian Academy of Sciences.

\section{STRUCTURE AND COMPOSITION OF PORPHYRIN COMPLEXES FROM OILS}

The structure of porphyrin is based on porphin composed of four pyrrole rings linked by unsaturated methane bridges (Fig. 1a). Oil porphyrins are mixtures of porphyrin molecules that differ in at least two factors, namely, the degree of cyclicity of the hydrocarbon environment linked to the porphin nucleus and the number of alkyl carbon atoms in the molecule (Fig. 1b). The possibility of varying the cyclicity of the substituents at the porphin nucleus of oil porphyrins is rather limited. In any oil, most porphyrins (80-95\%) are represented by alkyl porphyrins (series M, I) and monocycloalkanoporphyrins (series M-2, II; Fig. 2), having a mass two units smaller and containing a carbon bridge that links the pyrrole positions and 

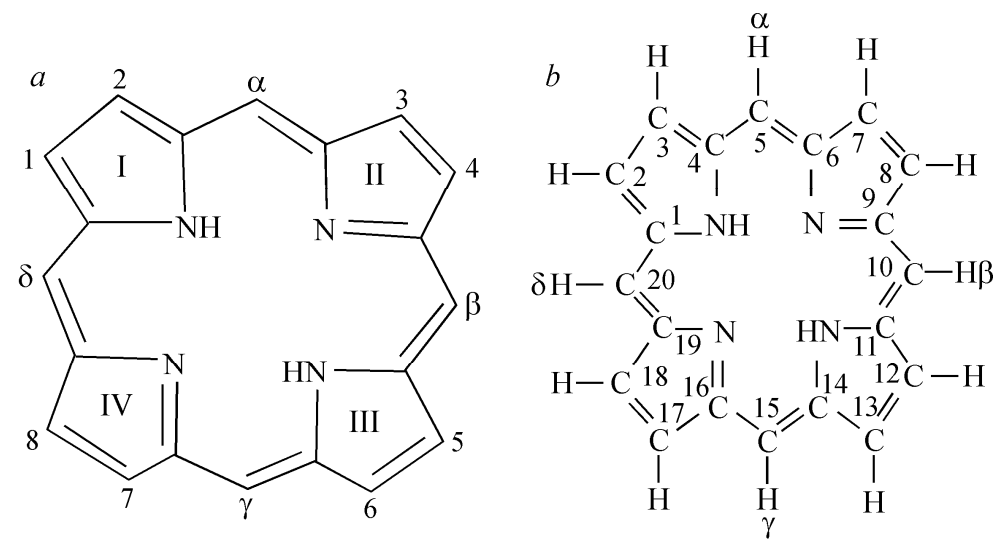

Fig. 1. Structural formula of porphin: (a) I-IV are the pyrrole rings in the porphin nucleus; $1-8$ are the atoms of the nucleus; $\alpha, \beta, \gamma$, and $\delta$ are the atoms of the methine bridges connecting the pyrrole rings; $(b)$ hydrocarbon frame.

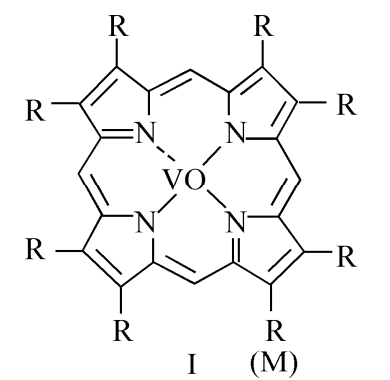

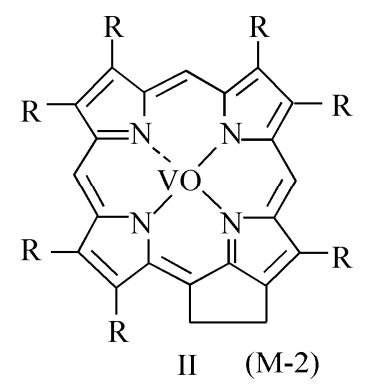

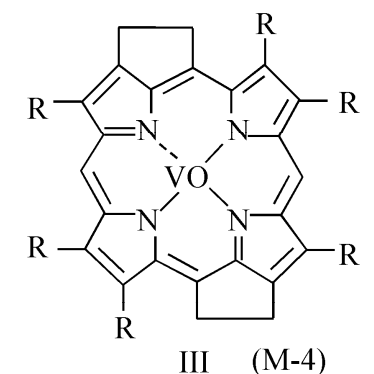

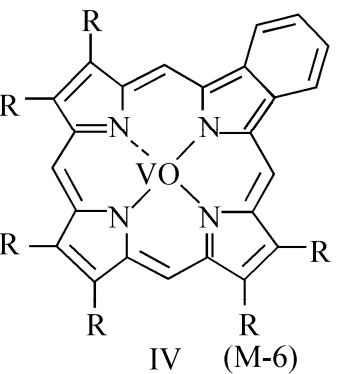

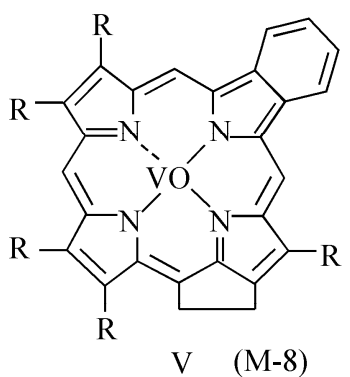

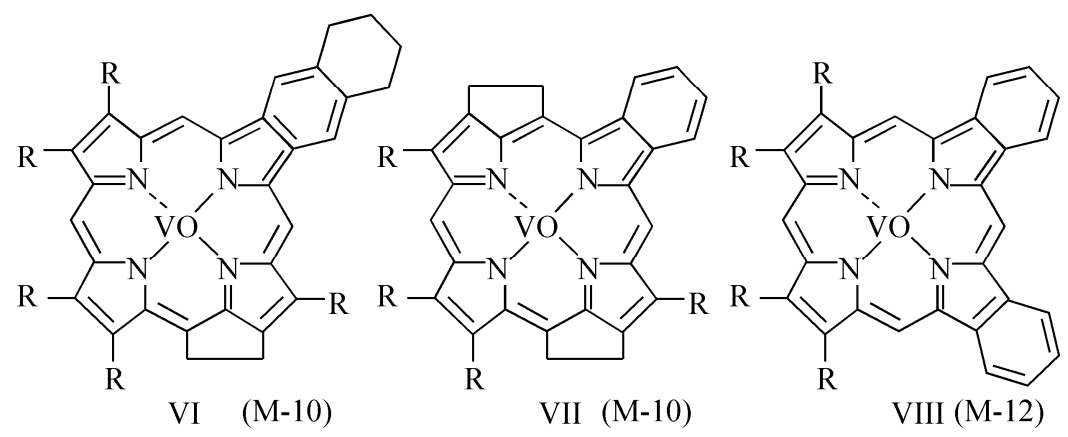

Fig. 2. Structures of porphyrins from oil. $\mathrm{R}$ is the hydrogen atom or an alkyl substituent with a length of the hydrocarbon chain from $\mathrm{C}_{1}$ to $\mathrm{C}_{12-15}$ [24].

the adjacent meso position. The content of compounds with these structural distinctions changes from oil to oil, and their concentrations are values of the same order of magnitude.

Few porphyrins (5-10\%) are based on more strongly condensed porphyrin compounds; these are minor homologous series with a deficiency of 4,6 , and 8 mass units relative to alkyl porphyrins (I). These compounds were assigned 
the structures of bicycloalkanoporphyrins (III), benzoporphyrins (IV), and cycloalkanomonobenzoporphyrins (V) [1, 23]. There are no compounds with these structural features among biological porphyrins of biological origin.

Metalloporphyrins based on all five structures mentioned above form continuous isobaric series in oil. The first members of the series generally contain 5-7 alkyl carbon atoms in the side substituents of the porphin ring; the end members contain up to 25-30 such atoms. In each series, homologs with 10-13 alkyl carbon atoms are present in maximum quantities [1].

Moreover, oil contains vanadyl porphyrins with greater numbers of condensed rings in the structure. Compounds from the M-10 series probably [24] correspond to cycloalkanoporphyrins containing a naphtheno-aromatic fragment (VI), or bicycloalkanobenzoporphyrins (VII). Compounds from the M-12 series are dibenzoporphyrins with adjacent (VIII) and/or opposite benzene rings. Like other series, this series porphyrins with increased aromaticity included continuous sets of homologs.

\section{MATERIALS AND PROCEDURE}

The samples for investigation were solid heterocyclic components of bitumoids from petroleogenetic rocks from various deposits of West and East Siberia, namely, asphaltenes, asphaltogentic acids, and resins (alcohol-benzene and benzene resins). The EPR spectra were studied at $T=77 \mathrm{~K}$ and $290 \mathrm{~K}$ on a Radiopan SE/X 2544 radiospectrometer $\left(\lambda=3.2 \mathrm{~cm}, f_{\bmod }=100 \mathrm{kHz}\right)$ with a double resonator. The sample was placed in one resonator, and $\mathrm{MgO}$ standard with $\mathrm{Mn}^{2+}$, in another (the standard allowed us to control the recording conditions and to introduce correcting factors in calculations of the concentration of the paramagnetic centers, which was determined using the $\mathrm{CuCl}_{2} \cdot 2 \mathrm{H}_{2} \mathrm{O}$ reference with the known number of spins).

\section{RESULTS AND DISCUSSION}

Figure $3 a$ shows the EPR spectrum recorded in the fractions of bitumoids under study. The characteristic anisotropic, axial symmetric spectrum of vanadyl complexes of 16 hyperfine lines had the same EPR parameters in all four fractions (Table 2) that coincided with those determined previously for natural samples, but different intensities.

Table 1 lists the concentrations $\left(N_{x}\right)$ of the vanadyl complexes and the accompanying free organic radical (FR), which is always present in vanadyl in natural samples. The largest values of $N_{x}$ for the vanadyl ion were reported for asphaltogenic acids, similar values were found for asphaltenes, and much smaller values, for resins and especially (sometimes the differences amounted to an order of magnitude) benzene resins. This distribution of vanadyl porphyrins over fractions is most often observed in natural samples, but sometimes the maximum concentration of vanadyl occurs in asphaltenes, probably because of the differences in the lithological parameters.

The intensity of the FR decreased in the series asphaltene (A) $\rightarrow$ asphaltogenic acid (A. c.) $\rightarrow$ alcohol-benzene resin (A.-b. r.) $\rightarrow$ benzene resin (B. r.). The largest value of $N_{x}$ for FR was always observed for asphaltenes; the concentration changed especially drastically (by a factor of 5-10) for the transition A $\rightarrow$ A. c. This characteristic ratio between fractions for FRs is always observed irrespective of lithology, sampling site, and the type of OM. This changes the intensity ratio of the $m=+1 / 2$ spectrum of vanadyl and FR in the fractions shown in Fig. $3 b$.

The spectra of resinous fractions showed a characteristic feature, namely, the shfs from four nitrogen atoms, which showed itself as the splitting of the strongest line of the $m=+1 / 2$ spectrum of the vanadyl ion into lines with the intensity ratio 1:4:10:16:19:16:10:4:1 $\left(a_{\mathrm{N}}=0.28 \mathrm{mT}\right.$, Fig. $\left.3 c\right)$. There was no splitting on the other lines of the spectrum. This spectral feature points to localization of the vanadyl ion in the porphyrin ring, where its nearest neighbors are four ${ }^{14} \mathrm{~N}$ atoms. This obviously "porphyrin type" spectrum with a clear-cut line splitting was always observed for alcohol-benzene resins at room temperature. For asphaltenes, asphaltogenic acids, and benzene resins, the spectrum contained only unsplit lines of the spectra of the vanadyl complexes. Spectrum recording at $77 \mathrm{~K}$ did not significantly change the picture; the parameters remained the

same, and the line splittings from the four nitrogen nuclei were also observed only for alcohol-benzene resins. These features 


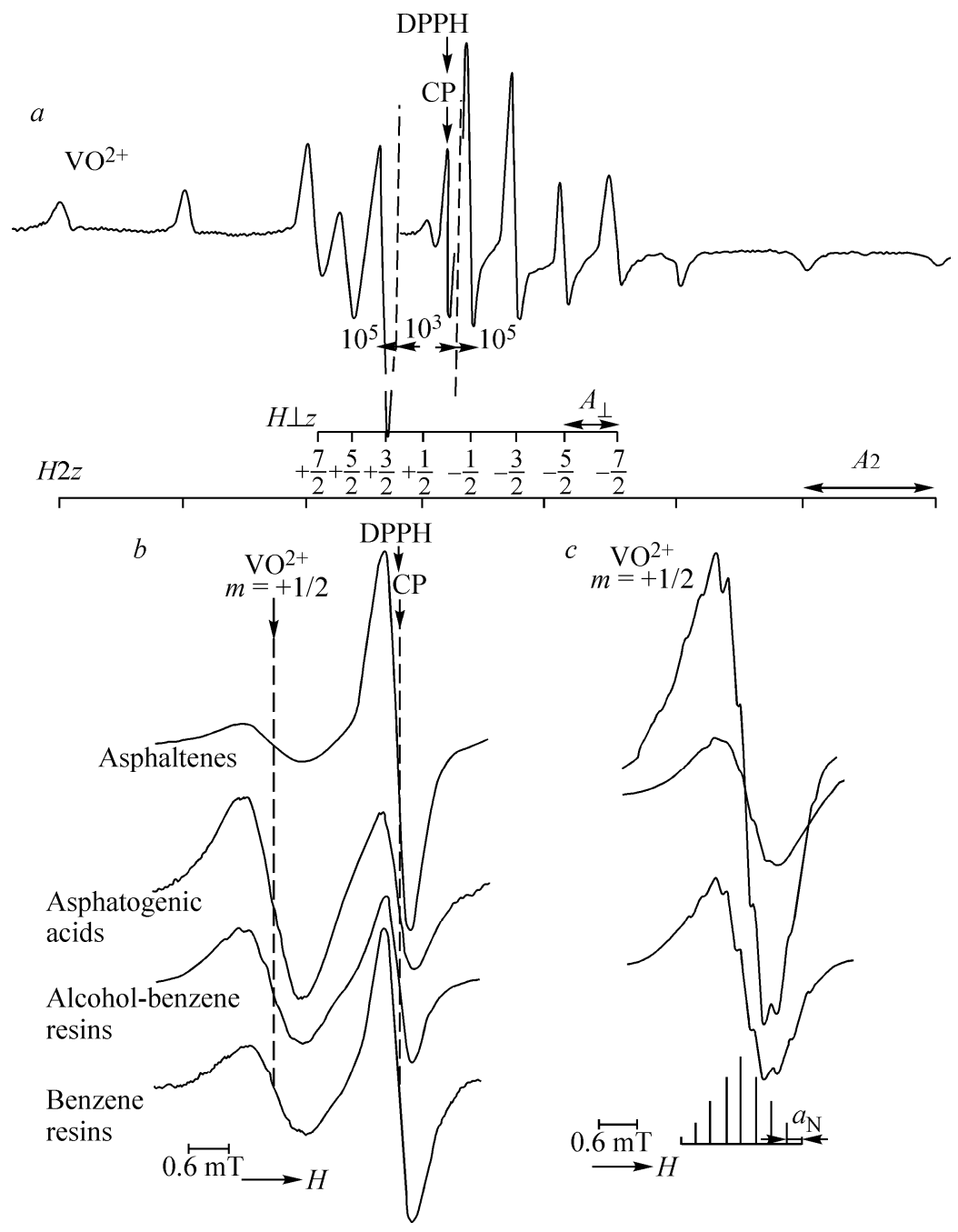

Fig. 3. (a) EPR spectrum of V(IV) complexes in the fractions of bitumoid; $(b)$ fragments of spectra with the ratio between the $m=+1 / 2$ line of the spectrum of vanadyl and FR lines in four fractions; $(c)$ the $m=+1 / 2$ line of the $\mathrm{VO}^{2+}$ spectrum in alcohol-benzene resins under different recording conditions and the theoretical scheme of the shfs from four ${ }^{14} \mathrm{~N}$ atoms.

allow us to speak about the existence of two spectra of the vanadyl ion in the fractions of these structural complexes (the hfs constants are the same), which are based on porphyrin, but probably differ in the second coordination sphere.

Investigation of the model (synthetic) vanadyl porphyrins of various types also revealed that the shfs from the nitrogen atoms showed itself ambiguously in the spectra; for etioporphyrins I [5] and II [25] the shfs was not observed, while for tetraphenyl porphyrins in various frozen solutions $\left(\mathrm{CS}_{2}, \mathrm{CHCl}_{3}\right.$, THF) superhyperfine splitting was recorded and its parameters were determined, $A_{\|}^{(\mathrm{N})}=2.9 \pm 0.05 \mathrm{G}, A_{\perp}^{(\mathrm{N})}=2.8 \pm 0.05 \mathrm{G}$ [15]. These porphyrins differ (Fig. 1 $a$ ) in the substituent in the pyrrole ring (EP I, EP II) and methine bridge (TPP, Table 2), i.e., in the second coordination sphere of the vanadyl ion.

Detailed analysis of the electronic structure of the vanadyl ion performed by Ballhausen and Gray [27] in the framework of the crystal field theory (MO LCAO) and then analysis of vanadyl porphyrin (MO LCAO) carried out by Kivelson and Lee [15] allowed the authors to explain the experimental parameters of the EPR and optical spectra. They suggested a scheme of the energy levels of MOs in the vanadyl porphyrin complex, which could be transformed according to the irreducible representations of $C_{4 v}$ symmetry. 
TABLE 1. Concentration of $\mathrm{VO}^{2+}$ Complexes $\left(N_{x} \cdot 10^{18}\right.$, rel. un.)* and Organic Radical FR $\left(N_{x} \cdot 10^{18} \mathrm{spin} / \mathrm{g}\right)$ in Four Fractions of Bitumoids from Petroleogenetic Rocks

\begin{tabular}{c|c|c|c|c|c|c|c|c}
\hline $\begin{array}{c}\text { Sample } \\
\text { No. }\end{array}$ & \multicolumn{2}{|c|}{ Asphaltenes } & \multicolumn{2}{c|}{ Asphaltogenic acids } & \multicolumn{2}{c|}{ Alcohol-benzene resins } & \multicolumn{2}{c}{ Benzene resins } \\
\cline { 2 - 8 } & $\begin{array}{c}\mathrm{VO}^{2+} \\
\text { (type I) }\end{array}$ & FR & $\begin{array}{c}\mathrm{VO}^{2+} \\
\text { (type I) }\end{array}$ & FR & $\begin{array}{c}\mathrm{VO}^{2+} \\
\text { type II) }\end{array}$ & FR & $\begin{array}{c}\mathrm{VO}^{2+} \\
\text { (type II) }\end{array}$ & FR \\
\hline 1 & 3.70 & 3.53 & 3.30 & 0.34 & 1.49 & 0.26 & + & 0.27 \\
2 & 5.89 & 4.37 & 12.39 & 0.75 & 2.24 & 0.49 & + & 0.33 \\
3 & 5.35 & 5.62 & 7.16 & 1.03 & 3.73 & 0.11 & + & 0.45 \\
4 & 17.69 & 0.44 & 13.86 & 0.05 & 0.10 & 0.50 & 0.26 & 0.05 \\
5 & 4.99 & 3.42 & 7.24 & 0.36 & 2.91 & 0.26 & 0.04 & 0.18 \\
6 & 5.51 & 2.37 & 11.95 & 0.62 & 5.68 & 0.30 & + & 0.32 \\
7 & 2.82 & 2.79 & 6.04 & 0.75 & 3.12 & 0.12 & + & 0.16 \\
8 & 1.13 & 5.47 & 1.88 & 0.72 & 0.56 & 0.27 & + & 0.15 \\
9 & 6.12 & 5.18 & 13.03 & 0.71 & 5.21 & 1.44 & + & 0.48 \\
10 & 5.59 & 4.08 & 5.57 & 1.34 & 1.55 & 0.67 & 0.09 & 0.29
\end{tabular}

The integrated intensity evaluated from the $m=-7 / 2(\times 8)$ line with an orientation $H \perp z$. Samples 1-6 are from a deposit from West Siberia; samples 7-10 are from East Siberia.

TABLE 2. Structure of Porphyrins*

\begin{tabular}{c|c|c|c|c|c|c|c|c|c|c|c|c}
\hline \multirow{2}{*}{ Porphyrins } & \multicolumn{7}{c|}{ Substituents in the pyrrole rings } & \multicolumn{3}{c}{$\begin{array}{c}\text { Substituents in the methine } \\
\text { bridges }\end{array}$} \\
\cline { 2 - 13 } & $\mathrm{H}$ & 2 & 3 & 4 & 5 & 6 & 7 & 8 & $\alpha$ & $\beta$ & $\gamma$ & $\delta$ \\
\hline Porphin & $\mathrm{H}$ & $\mathrm{H}$ & $\mathrm{H}$ & $\mathrm{H}$ & $\mathrm{H}$ & $\mathrm{H}$ & $\mathrm{H}$ & $\mathrm{H}$ & $\mathrm{H}$ & $\mathrm{H}$ & $\mathrm{H}$ & $\mathrm{H}$ \\
Etioporphyrin I & $\mathrm{M}$ & $\mathrm{E}$ & $\mathrm{M}$ & $\mathrm{E}$ & $\mathrm{M}$ & $\mathrm{E}$ & $\mathrm{M}$ & $\mathrm{E}$ & $\mathrm{H}$ & $\mathrm{H}$ & $\mathrm{H}$ & $\mathrm{H}$ \\
Etioporphyrin II & $\mathrm{M}$ & $\mathrm{E}$ & $\mathrm{E}$ & $\mathrm{M}$ & $\mathrm{M}$ & $\mathrm{E}$ & $\mathrm{E}$ & $\mathrm{M}$ & $\mathrm{H}$ & $\mathrm{H}$ & $\mathrm{H}$ & $\mathrm{H}$ \\
Tetraphenylporhyrin & $\mathrm{H}$ & $\mathrm{H}$ & $\mathrm{H}$ & $\mathrm{H}$ & $\mathrm{H}$ & $\mathrm{H}$ & $\mathrm{H}$ & $\mathrm{H}$ & $\mathrm{Ph}$ & $\mathrm{Ph}$ & $\mathrm{Ph}$ & $\mathrm{Ph}$
\end{tabular}

*Data of Table 1 from [23]; $\mathrm{M}$ is methyl $\left(-\mathrm{CH}_{3}\right)$; E, ethyl $\left(-\mathrm{CH}_{2} \mathrm{CH}_{3}\right)$; Ph, phenyl $\left(-\mathrm{C}_{6} \mathrm{H}_{5} \mathrm{OH}\right)$; and $\mathrm{H}$, hydrogen.

The $\mathrm{V}-\mathrm{O}$ bond in the complex is dominant; this is a strong $\sigma$ bond ( $a_{1}$ symmetry) between the $s p_{\sigma}$-hybrid orbital of oxygen and the $\left(4 s+3 d_{z^{2}}\right)$-hybrid orbital of vanadium. The odd electron in the complex lies on the $b_{2 g}^{*}$ antibonding orbital, which is completely localized on the $d_{x y}$ atomic orbital of vanadium (in the weak $\pi$ bond approximation in the plane of the nitrogen atoms). The first and second excited states are the $e_{\pi}^{x}$ and $b_{1 g}^{*}$ MOs, respectively [15]. As can be seen from Table 3 , there is no spin density on the nitrogen atoms, and no shfs should be observed from them in the EPR spectra, which was indeed observed in the majority of experiments (in natural asphaltenes and model etioporphyrins I, II). The isotropic shfs from nitrogen was recorded for tetraphenylporphyrins because of the configuration interaction and the presence of an electron in the excited states with the dominant excitation $b_{1 g}^{2} b_{2 g}^{*} \rightarrow b_{1 g} b_{1 g}^{*} b_{2 g}^{*}$, where the $b_{1 g}$ and $b_{1 g}^{*}$ (bonding and antibonding) MOs include the $d_{x^{2}-y^{2}}$ atomic orbital of vanadium and the hybrid $\left(s p^{2}\right) \sigma_{I}$ orbitals of the nitrogen atoms directed toward the vanadium nucleus [15].

The methine bridges of tetraphenylporphyrins contain four phenyl $\left(\mathrm{C}_{6} \mathrm{H}_{5} \mathrm{OH}\right)$ ring groups, which evidently affect the parameters of vanadyl porphyrin by changing the interatomic distances, namely, the distances from vanadium to the equivalent pyrrole nitrogen atoms $d(\mathrm{~V}-\mathrm{N})$. The $\mathrm{V}-\mathrm{O}$ distance is $1.59 \AA$ in the vanadyl ion; $d(\mathrm{~V}-\mathrm{N})=1.9 \AA$ between vanadium and the pyrrole nitrogen atoms in porphyrins [15]. Researchers reported that the porphyrin molecule could be 
TABLE 3. EPR Spectrum Parameters of Vanadyl Porphyrins

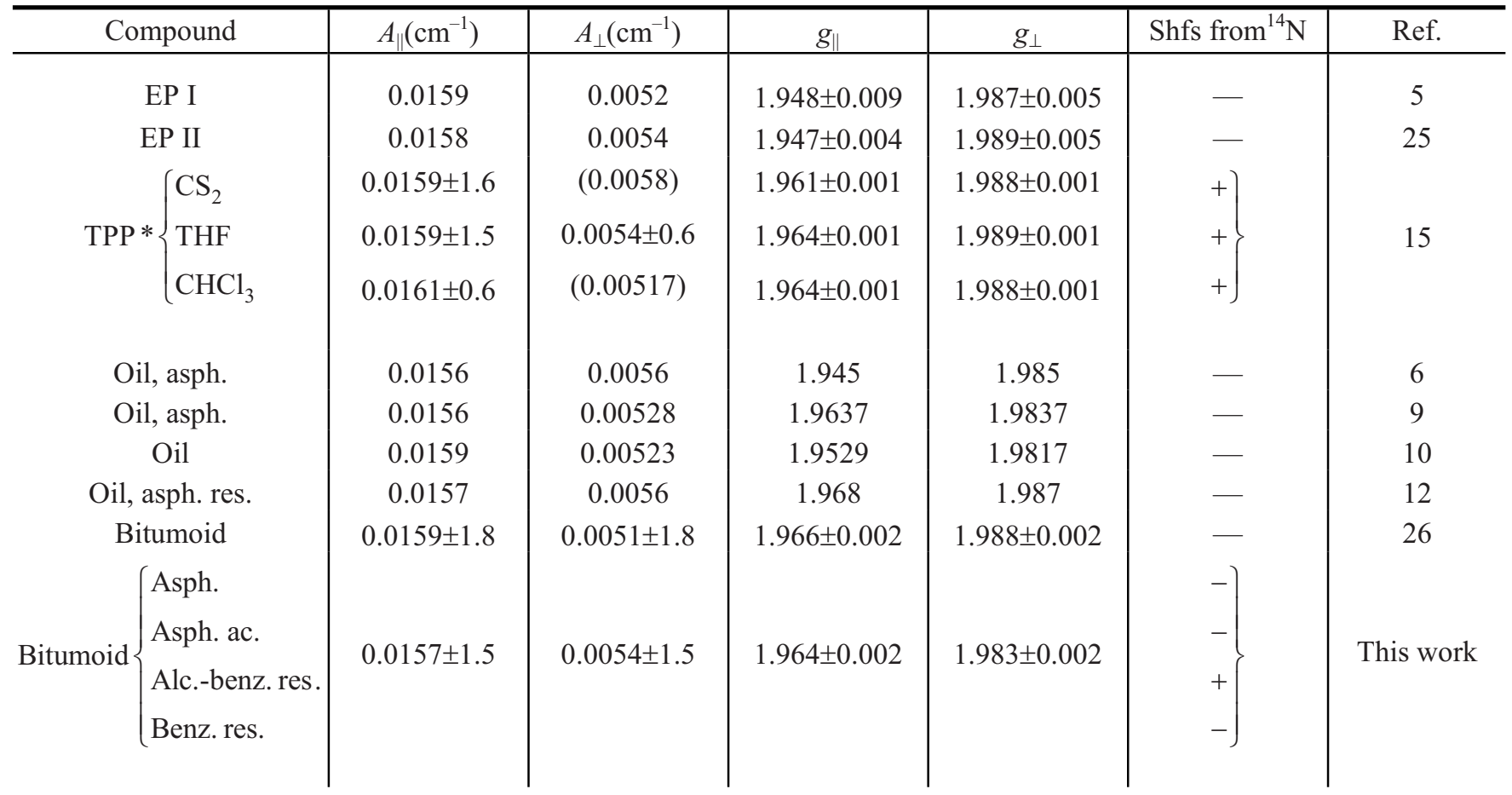

Notation: EP is etioporphyrin; TPP*, tetraphenylporphyrin in frozen THF solutions of $\mathrm{CS}_{2}$ and $\mathrm{CHCl}_{3}$; $\mathrm{Asph}$. are asphaltenes; Asph. ac., asphaltogenic acids; Alc.-benz. res., alcohol-benzene resins; Benz. res., benzene resins.

slightly expanded if it incorporated a large metal ion (platinum) [28] or compressed in the presence of a small cation ( $\mathrm{Mg}, \mathrm{Ni}$ and others) [29]. It was also reported that $d(\mathrm{~V}-\mathrm{N})$ changed from $0.28 \AA$ to $0.65 \AA$ in chelates [14]. All four pyrrole rings lie in the same plane in the molecule, but (as in the case of chlorophyll) the appearing fifth carbocyclic ring deformed the major porphyrin nucleus [30]. The coefficients in the wave functions of MOs, the overlap integrals $S$ are the functions of $d(\mathrm{~V}-\mathrm{N})$; that is, one can argue that changes in the second coordination sphere in the porphyrin complex change the spin density distribution of the odd electron, giving rise to excited configurations so that one can observe the shfs from the nitrogen atoms.

In natural oils, the porphyrin complexes mostly form two series, alkyl porphyrins (M) and cycloalkane porphyrins (M-2) containing an isocyclic ring (Fig. 4). The mass spectrometric literature data on oil porphyrins and the electronic absorption spectra indicate that the fraction of these two series of oil porphyrins is larger than the fractions of more highly condensed porphyrin compounds from secondary homologous series (M-4, M-6, etc.) [13,31]. They have biological precursors (chlorophyll, hemin). The ratio of the porphyrins of the M and M-2 homologous series in oils can vary and depends on the composition (mostly, $(\mathrm{M}-2) / \mathrm{M}<1$ ) [32]. The relative content of the $\mathrm{M}$ and $\mathrm{M}-2$ homologs in oils evaluated from the intensity of the Soret band $(398 \mathrm{~nm})$ in the electronic asbsorption spectra was $60 \%$ and $40 \%$, respectively [31]. Based on these data one can assume that the EPR spectrum having no shfs and splittings in asphaltenes, asphaltogenic acids, and benzene resins is due to the vanadyl complexes in etioporphyrins (M), while the clearly split spectrum of alcoholbenzene resins is due to the complexes in desoxophylloerythroetioporphyrins (M-2). The nearest surroundings of the $\mathrm{VO}^{2+}$ complexes are similar in them (Fig. 4), and hence we have identical hfs parameters, while the additional shfs is observed only for one of the complexes (at $290 \mathrm{~K}$ and $77 \mathrm{~K}$ ) (this may be explained by the difference in the second coordination sphere, or by the presence of an isocyclic ring in porphyrins (M-2)). In Table 1, the spectra of $\mathrm{VO}^{2+}$ are designated as type I and II in the M (unsplit) and M-2 (split) homologs, respectively.

As mentioned previously [9], the similarity of the hfs parameters in the EPR spectra (the differences are within the limits of the measurement error, Table 3) prevents them from being used for identification of the types of porphyrins in the natural samples. However, investigation of the fractions showed that the ambiguity of the shfs from the nitrogen atoms in the 

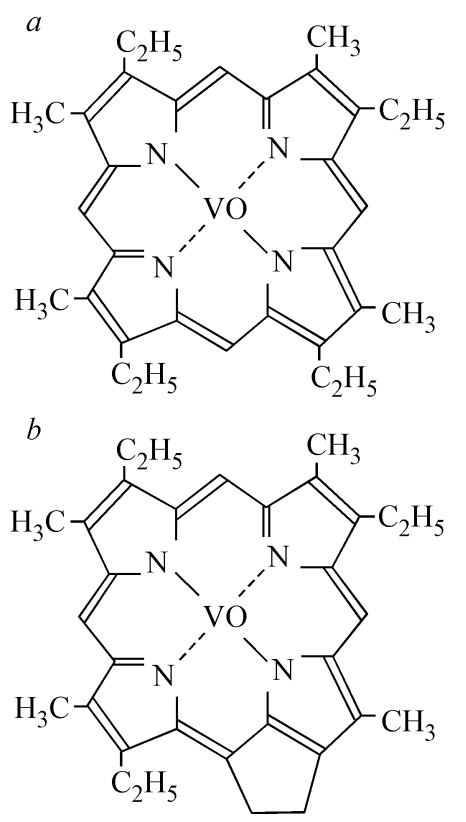

Fig. 4. Structural formulas of the vanadyl complexes: $(a)$ etioporphyrin (M) and (b) desoxophylloerythroporphyrin $(\mathrm{M}-2)$.

EPR spectra of different vanadyl porphyrins (its presence or absence) is explained by the structural features of the porphyrins and by changes in the second coordination sphere of the vanadyl ion (the presence of this ion in different homologs, namely, in M-2 and $\mathrm{M}$, respectively).

Note that substitution of the vanadyl ligands in the first coordination sphere (e.g., of two nitrogen atoms) by two oxygen atoms (as in the case of model $\beta$-ketamines) changes the hfs parameters significantly $\left(A_{\|}=18.3-17.6 \mathrm{mT}, A_{\perp}=6.4-\right.$ $6.1 \mathrm{mT}$ ) [33].

The character of changes in the EPR spectral parameters of the vanadyl ion caused by changes in its environment was discussed in numerous publications [34, 35]. This is the second (after the $\mathrm{Cu}$ (II) complex) well-studied complex of transition metal ions in aqueous solutions. It was reported that the vanadyl ion surrounded by four nitrogen atoms in different frozen solutions did not show any shfs from the ${ }^{14} \mathrm{~N}$ either [15], which corresponded to the suggested scheme of energy levels [27]. Studies of vanadyl porphyrins in different solutions are scarce, which explains that the shfs on the ${ }^{14} \mathrm{~N}$ nuclei is still an open question.

The oil vanadyl porphyrin complexes under study are part of the complex natural organic compounds (oil, bitumoids), which suggests that they are involved in $\pi$ type interactions with various molecular structures, in particular, with aromatic layers $[14,15]$. It was assumed that this interaction could explain the changes in $d(\mathrm{~V}-\mathrm{N})$ and hence the observation of the shfs in the EPR spectrum [14]. However, comparative analysis of the concentrations of the organic FR, which reflected aromaticity of the samples and vanadyl porphyrin complexes in four fractions (Table 1), showed that the indicator features of the spectrum (the presence of shfs) are due to changes in the structure, namely, changes in the second coordination sphere, and to the presence of an isocyclic ring in the M-2 homologs of natural porphyrins and of a phenyl group in the methine bridges of synthetic tetraphenyl porphyrins [15]. Even significant (tenfold or larger) differences in the FR concentrations in asphaltenes and asphaltogenic acids are not accompanied by changes in the spectral parameters and the shfs is not observed in asphaltenes. Analysis of the element composition of fractions and the observed effect in the EPR spectra did not reveal any correlation with the $\mathrm{H} / \mathrm{C}$ atomic ratio either. 
EPR studies of oils, bitumoids, their fractions (asphaltenes in most published cases), and kerogens showed that the paramagnetic centers were related to the matrix composition. The EPR parameters of the organic radical ( $g$ factor, $\Delta H, N_{x}$ ) depend on the type of the organic substance, its conversion, the number of aliphatic and aromatic motifs (H/C ratio), and are used for evaluating the paleogeothermal gradients, etc. [36, 37].

The spectra of the $\mathrm{V}^{4+}$ (vanadyl, $\mathrm{VO}^{2+}$ ) complexes indicate that the matrix contains porphyrins that are biomarkers used for diagnostics of petroleogenetic deposits. Vanadyl porphyrins are stable complexes; therefore, data about their concentration are primarily used for solving problems of petroleum geology, e.g., for evaluating the relative productivity of deposits, investigating their geological structure, determining the hydrodynamic relation between beds, performing oil stratification, and solving other problems that appear during oil pool survey and development [31].

The results of this work make it possible to determine the type of porphyrins in the (M, M-2) fractions from the presence or absence of the shfs from nitrogen atoms in the EPR spectrum and especially to determine the (M-2)/M ratio that characterizes the redox conditions of oil generation or the variation of temperature at the catagenesis stage. All features of the EPR spectra reported in this work, namely, the distribution of porphyrins over fractions, registration of the shfs from the nitrogen atoms in the spectrum of vanadyl in alcohol-benzene resins, and the typical change in the concentration of the organic radical that correlates with aromaticity of fractions are also observed for natural oil fractions. These tendencies in the EPR spectra were tested on a large collection of fractions of natural bitumoids and oils ( 600 samples), and, together with geological and geochemical data for the samples, the results of this analysis will be the subject of our future publication. The experimental data of this work will probably find use in geological and geochemical research and will lay the groundwork for future theoretical calculations of complex coordination complexes such as natural vanadyl porphyrins.

\section{CONCLUSIONS}

1. The structure of the porphyrin complexes correlates with the characteristic feature of the EPR spectrum of the vanadyl ion in natural bitumoids, namely, the presence or absence of superhyperfine splitting on the nuclei of four nitrogen atoms.

2. Changes in the second coordination sphere of the vanadyl ion, namely, substitutions in the methine bridges of porphyrins with respect to the substitutions in the pyrrole rings are the major factors that affect the spin density distribution of the odd electron and give rise to the excited configurations, leading to the shfs in the spectrum.

3. According to the presence or absence of the shfs in the EPR spectra of the fractions of natural bitumoids and oils

one can determine the type of porphyrin (M, M-2); the ratio between these types is an important parameter of the redox conditions of oil generation.

\section{REFERENCES}

1. N. K. Nadirov, A. V. Kotova, V. F. Kam'yanov, et al., New Olis of Kazakhstan and Their Use: Metals in Oils [in Russian], Nauka, Alma-Ata (1984).

2. S. A. Punanova, Geokhimiya, No. 8, 959 (2004).

3. S. A. Punanova, ibid., No. 9, 893 (1998).

4. A. Treibs, Ann. Chem., 509, 103 (1934).

5. D. E. O'Reilly, J. Chem. Phys., 29, No. 5, 1188 (1958).

6. A. V. Il’yasov, N. S. Garif'yanov, and Yu. M. Ryzhmanov, Khim. Tekhnol. Topliv Masel, No. 1, 28 (1961).

7. A. J. Saraceno, D. T. Fanale, and N. D. Coggeshall, Anal. Chem., 33, No. 4, 500 (1961).

8. E. M. Roberts, R. L. Rutledge, and A. P. Wehner, ibid., 33, No. 13, 1879 (1961).

9. I. N. Marov, V. K. Belyaeva, Yu. B. Gerlit, et al., Geokhimiya, No. 1, 20 (1972).

10. S. S. Savkevich, Yu. V. Bogachev, L. P. Dergacheva, and V. Z. Drapkin, Treatises of VNIGRI, Leningrad (1980). 
11. B. F. Alekseev, A. M. Belonogov, and Yu. V. Bogachev, Magnetic Resonance in Studies of Natural Objects [in Russian], Nedra, Leningrad (1987).

12. Z. P. Altukhova, V. R. Antipenko, and S. P. Marchenko, Composition and Properties of the Components of Oils from the Nizhnevartovsk Vault. Scientific Treatises [in Russian], G. F. Bolshakov (ed.), Tomsk (1984).

13. T. F. Yen, L. J. Bocher, J. P. Dickie, et al., J. Inst. Petrol. London, 55, No. 542, 87 (1969).

14. T. F. Yen, Naturwissenschaften, 58, No. 5, 267 (1971).

15. D. Kivelson and S. K. Lee, J. Chem. Phys., 41, No. 7, 1896 (1964).

16. A. É. Kontorovich, L. S. Borisova, and E. P. Strekhletova, Geokhimiya, No. 6, 853 (1995).

17. A. É. Kontorovich and L. S. Borisova, Geol. Geofiz., No. 3, 28 (1989).

18. A. É. Kontorovich and L. S. Borisova, Geokhimiya, No. 11, 1660 (1994).

19. M. Bakr, M. Akiyama, Y. Sanada, and T. Yokono, Org. Geochem., 9, No. 6, 321 (1986).

20. V. A. Uspenskii, K. F. Rodionova, A. I. Gorskaya, and A. P. Shishkova (eds.), Analysis of Bitumens and Scattered Organic Matter of Rocks. Manual (for geological survey laboratories) [in Russian], Nedra, Leningrad (1966).

21. A. É. Kontorovich (ed.), Modern Analytical Methods in Organic Geochemistry [in Russian], SNIIGGIMS, Novosibirsk (1973).

22. V. A. Uspenskii (ed.), Methods in Bituminological Research [in Russian], Nedra, Leningrad (1975).

23. Yu. M. Abyzgildin, Yu. I. Mikhailyuk, K. S. Yarullin, and A. A. Ratovskaya, Porphyrins and Metalloporphyrin Complexes of Oils [in Russian], Nauka, Moscow (1977).

24. V. R. Antipenko, G. S. Pevneva, and V. I. Titov, Dokl. Akad. Nauk SSSR, 283, No. 3, 626.

25. E. M. Roberts, W. S. Koski, and W. S. Caughey, J. Chem. Phys., 34, 591 (1961).

26. V. A. Chichenov, I. N. Marov, V. K. Belyaeva, et al., Geokhimiya, No. 1, 112 (1975).

27. C. J. Ballhausen and H. B. Gray, Inorg. Chem., 1, No. 1, 111 (1962).

28. S. Tomonura, Chem. Ind., 8, 505 (1955).

29. M. B. Crute, Acta Crist., 12, 24 (1959).

30. O. V. Serebrennikova and T. V. Belokon', Geochemistry of Porphyrins [in Russian], Nauka, Novosibirsk (1984).

31. R. N. Nasirov, Paramagnetism of Oils and Rocks of the Caspian Region [in Russian], Nedra, Moscow (1993).

32. N. I. Shilonosova and O. V. Serebrennikova, Composition and Properties of Oils from the Nizhnevartovsk Vault. A Collection of Treatises [in Russian], G. F. Bolshakov (ed.), Tomsk (1984).

33. L. J. Boucher, E. C. Tynan, and T. F. Yen, Inorg. Chem., 7, No. 4, 731 (1968).

34. I. N. Marov and N. A. Kostromina, EPR and NMR in Coordination Chemistry [in Russian], Nauka, Moscow (1979).

35. H. A. Kuska and M. T. Rogers, EPR of Transition Metal Complexes [in Russian], Mir, Moscow (1970).

36. Z. Aizenshtat, I. Pinsky, and B. Spiro, Org. Geochem., 9, No. 6, 321 (1986).

37. Q. Nansheng and W. Jiyang, ibid., 28, Nos. 1/2, 77 (1998). 